several trials made with 60-inch plates from which he found that a large number of nebulae were required on each plate in order to obtain accurate results.

The question of establishing a few additional Selected Areas was discussed and a motion by Adams to have the President appoint a sub-commission to deal with this matter was adopted.

\title{
COMMISSION 33 (STELLAR STATISTICS)
}

\author{
President: Prof. Bertil Lindblad. \\ Secretaries: Prof. H. L. Vanderlinden and Dr C. Schalén.
}

The Commission met on August 4, at 9.30.

The report prepared by the President of the Commission was adopted. A few important and interesting points were further discussed.

(I) $\mathrm{Mr}$ Bok gave an outline of a general programme of determining radial velocities by means of objective-prism spectra. Measurable spectra can be obtained for stars as faint as $\mathrm{ro}^{\mathrm{m}} \cdot \mathbf{2}$ using one comparison line; the probable error is of the order of $\pm 20 \mathrm{~km}$. per sec. A greater precision should be obtained if more comparison stars were available.

(2) Mr Shapley made the following proposal concerning the appointment of a sub-commission for establishing co-operation on the construction of magnitude sequences.

"The Commission on Stellar Statistics endorses the proposal that the Commission on Stellar Photometry (25) consider the appointment of a sub-commission on magnitude sequences, noting that for work on stellar distribution, variable stars, external galaxies, faint asteroids and faint proper-motion stars the need of more precise photographic and visual magnitudes is very great."

The motion was adopted by the Commission.

(3) Mr Vyssotsky made a few remarks concerning extensive plans for classifying stellar spectra.

(4) Mr Andersen summarized a paper by himself bearing on the general theoretical basis of probability in statistics.

(5) Mr Mineur called attention to the importance of securing radial velocities of galactic clusters, as they should allow a good determination of the distance of the galactic centre. Radial velocities of a greater number of globular clusters are also extremely desirable.

\section{COMMISSION 35 (CONSTITUTION OF THE STARS)}

\author{
President: Sir ARThUR EdDINGTON. \\ Secretary: Prof. B. Strömgren.
}

The Commission first discussed the problem of the density distribution in the interior of the stars. The President summarized the arguments leading to stellar models characterized by a polytropic index of $I \frac{1}{2}$ at the centre which increases outwards to a value between 3 and $3 \frac{1}{2}$ near the outside. The President then commented 